(3)

\title{
ANTIBACTERIAL ACTIVITIES OF ETHANOLIC EXTRACT OBTAINED FROM RHODODENDRON MYRTIFOLIUM SCHOTT \& KOTSCHY LEAVES AGAINST CLINICALLY ISOLATED BACTERIAL STRAINS
}

\author{
Honcharenko Vitaliy ${ }^{1}$, Tkachenko Halyna ${ }^{2}$, \\ Prokopiv Andriy ${ }^{1,3}$, Nachychko Viktor ${ }^{1,3}$, Sosnovsky Yevhen ${ }^{3}$, \\ Góralczyk Anna ${ }^{2}$, Osadowski Zbigniew ${ }^{2}$
}

\footnotetext{
${ }^{1}$ Department of Botany, Faculty of Biology, Ivan Franko National University in Lviv, Lviv, Ukraine

${ }^{2}$ Institute of Biology and Earth Sciences, Pomeranian University in Słupsk, Poland

${ }^{3}$ Botanic Garden of Ivan Franko National University in Lviv, Lviv, Ukraine
}

Received: 3. 12. 2019 Revised: 8. 12. $2019 \quad$ Published: 10. 12. 2019

The plants belonging to the genus Rhododendron L. and isolated compounds demonstrate diverse biological activities including anti-inflammatory, analgesic, anti-microbial, anti-diabetic, insecticidal and cytotoxic activity, as well as antibacterial activity. Our study was designed the effects of Rhododendron myrtifolium Schott \& Kotschy leaf extract against bacterial strains were monitored in vitro by the disk diffusion method. The aim of this study was to assess possible antibacterial effects of an ethanolic extract derived from Rhododendron myrtifolium leaves against Citrobacter freundii, Enterobacter cloacae, Klebsiella pneumoniae, and Escherichia coli strain locally isolated from human biological fluids. Thus, the study contributes to on-going investigations on the bioactivity potential of plant species such as the Rhododendron. Leaves of Rhododendron myrtifolium were harvested on the side of the road between the Menchul valley and Rogneska valley (Kvasy village, Rakhiv district, Zakarpattia region, Ukraine). The results revealed that extract exerts antibacterial activity against Citrobacter freundii. However, the Enterobacter cloacae, Klebsiella pneumoniae, and Escherichia coli were resistant to R. myrtifolium leaf extract. Maximum in vitro inhibition was scored against Citrobacter freundii, followed by Escherichia coli, Klebsiella pneumoniae, and Enterobacter cloacae, which presented inhibition zones of (12.1 \pm 0.9$) \mathrm{mm}$, $(9.1 \pm 0.5) \mathrm{mm},(7.5 \pm 0.6) \mathrm{mm}$, and $(7.2 \pm 0.5) \mathrm{mm}$, respectively. In the case of the positive controls, $96 \%$ ethanol possesses a mild antibacterial effect, which presented inhibition zones of $(6.5 \pm 0.7) \mathrm{mm}$. The results from the screening study performed by the disc diffusion method revealed that $R$. myrtifolium possesses a mild antibacterial activity against $C$. freundii. However, further investigation is needed to determine the bioavailability of the active compounds and to determine the dose and toxicity before it can be used as therapeutic agents.

Keywords: Rhododendron, leaf extracts, agar disk diffusion assay, antibacterial activity, inhibition zone diameter

\footnotetext{
*Corresponding author: Halyna Tkachenko, Institute of Biology and Earth Sciences, Pomeranian University in Słupsk, Arciszewski 22b, 76-200 Słupsk, Poland $\triangle$ tkachenko@apsl.edu.pl
} 


\section{Introduction}

Antimicrobial resistance has become a pre-eminent concern in medicine and public health. This problem is widespread, and the causative factors are uncontrolled (Mah and Memish, 2000). Control of infections caused by multi-drug resistant Gram-positive and Gram-negative bacteria has become a major problem in various countries in the prevention of infectious diseases. Currently, the spread of multi-drug resistant bacteria is not only through nosocomial infections, but also occurs in the community (Radji et al., 2013). Several multidrug resistant bacteria that are most commonly found, especially through nosocomial infections, are Enterococcus faecium, Staphylococcus aureus, Klebsiella pneumoniae, Acinetobacter baumannii, Pseudomonas aeruginosa, and Enterobacter spp. (Rice, 2008). In the past few decades, these strains become increasingly important pathogens in hospitals and play an important role in the colonization and infection of hospitalized patients by a variety of nosocomial infections including bacteremia, urinary tract infections, and nosocomial pneumonia (Radji et al., 2013).

Treatment of these infections is often very difficult due to the cross-resistance of these bacteria with a large group of antibiotics. Therefore, it seems reasonable to explore alternative antimicrobial agents for control multi-drug resistant bacteria. Recently, there has been growing interests to find antimicrobial compounds from medicinal plant extracts as an alternative approach to discover new antimicrobial compounds (Ríos and Recio, 2005; Radji et al., 2013). Rhododendron species have been proved to possess medicinal and health promotion properties, including the ability to inhibit the growth of some types of pathogenic bacteria (Innocenti et al., 2010; Silici et al., 2010; Popescu and Kopp, 2013; Rezk et al., 2015; Wang et al., 2015; Li et al., 2016; Hakeem Said et al., 2017; Shrestha et al., 2017).

The genus Rhododendron L. (Ericaceae) is one of the most species-rich among angiosperms, comprising over 1000 species spreading across the northern hemisphere and with the center of diversity in southeastern Asia (Irving and Hebda, 1993). These plants are morphologically diverse, including evergreen and deciduous shrubs, subshrubs, and trees, mostly terrestrial but sometimes chasmophytic or epiphytic, with greyish-brown striate bark, spirally arranged branches, and leaves, often in pseudo-whorls, and umbellate to pyramidal racemes of 1-30 conspicuous fragrant flowers. Because of its foliage and flowers, the genus is well-known in ornamental cultivation and gardening, with numerous varieties artificially bred thanks to rhododendrons' natural ability to interspecific hybridization (Cullen, 2005). A noteworthy European member of the genus is $R$. myrtifolium Schott \& Kotschy, an evergreen clump-forming dwarf shrub up to $50 \mathrm{~cm}$ in height, occurring in high-mountain habitats of the eastern and southern Carpathian Mountains and northern Balkans, largely within altitudes of $1,400-2,500 \mathrm{~m}$. The species is featured in small narrowly elliptic to obovate coriaceous leaves abaxially covered with glandular scales containing essential oils, terminal inflorescences of tubular-campanulate pinkish flowers, and long-pedunculate dry multilocular capsules containing numerous diminutive seeds (Cullen, 1980; Mircea, 2005; Boratyński et al., 2006; Voloschuk and Prokopiv, 2011). Although endangered in countries of its distribution, R. myrtifolium has been used in folk medicine for the preparation of herbal teas (Dihoru and Boruz, 2014; Nedelcheva and Draganov, 2014) and presents a major touristic attraction during 
its mass flowering period in mountains (Rivers, 2017). Its evolutionary closest relatives, R. ferrugineum L. and R. hirsutum L. (e.g., Sosnovsky et al., 2017) have been shown to possess cytotoxic, antibacterial, and antiviral effects of their extracts (Louis et al., 2010; Gescher et al., 2011; Seephonkai et al., 2011; Rezk et al., 2015b), while the biochemical features and bioactive potentials of $R$. myrtifolium remain unexplored.

Rhododendron species have been traditionally used in China, Nepal, Russia, and North America against inflammation, pain, skin ailments, common cold, and gastrointestinal disorders and for treating human diseases like asthma and skin diseases. These species are known to be a good source of polyphenolic plant secondary plant metabolites (Shrestha et al., 2017). The plant extracts belonging to the genus Rhododendron and isolated compounds demonstrated diverse biological activities including anti-inflammatory, analgesic, anti-microbial, antidiabetic, insecticidal and cytotoxic activity (Popescu and Kopp, 2013), as well as antibacterial activity (Innocenti et al., 2010; Silici et al., 2010; Popescu and Kopp, 2013; Rezk et al., 2015; Wang et al., 2015; Li et al., 2016; Hakeem Said et al., 2017; Shrestha et al., 2017).

The aim of this study was to assess possible antibacterial effects of an ethanolic extract derived from Rhododendron myrtifolium leaves against Citrobacter freundii, Enterobacter cloacae, Klebsiella pneumoniae, and Escherichia coli strain locally isolated from human biological fluids. Thus, the study contributes to on-going investigations on the bioactivity potential of plant species such as the Rhododendron. Hence, the effects of Rhododendron myrtifolium leaf extract against bacterial strains were monitored in vitro by the disk diffusion method.

\section{Materials and methodology}

\section{Collection of Plant Materials}

Leaves of Rhododendron myrtifolium were harvested on the side of the road between the Menchul valley and Rogneska valley (Kvasy village, Rakhiv district, Zakarpattia region, Ukraine; N $48^{\circ} 09^{\prime} 28.4^{\prime \prime}$, E $24^{\circ} 20^{\prime} 05.6^{\prime \prime}, 1,485 \mathrm{~m}$ a.s.l.) (Figure 1). Plant samples were thoroughly washed to remove all the attached materials and used to prepare the ethanolic extract.

\section{Preparation of Plant Extracts}

Freshly leaves were washed, weighed, crushed, and homogenized in 96\% ethanol (in proportion $1: 19, \mathrm{w} / \mathrm{w}$ ) at room temperature. The extract was then filtered and investigated for antimicrobial activity.

\section{Antimicrobial susceptibility testing}

Non-repetitive clinical strains of isolated from biological materials infected patients were collected from Koszalin Hospital during March-April, 2019. The purity, as well as the identity of isolate, was confirmed in the laboratory conditions by standard microbiological methods and were interpreted according to the guidelines of the Clinical Laboratory Standards Institute (2014). 


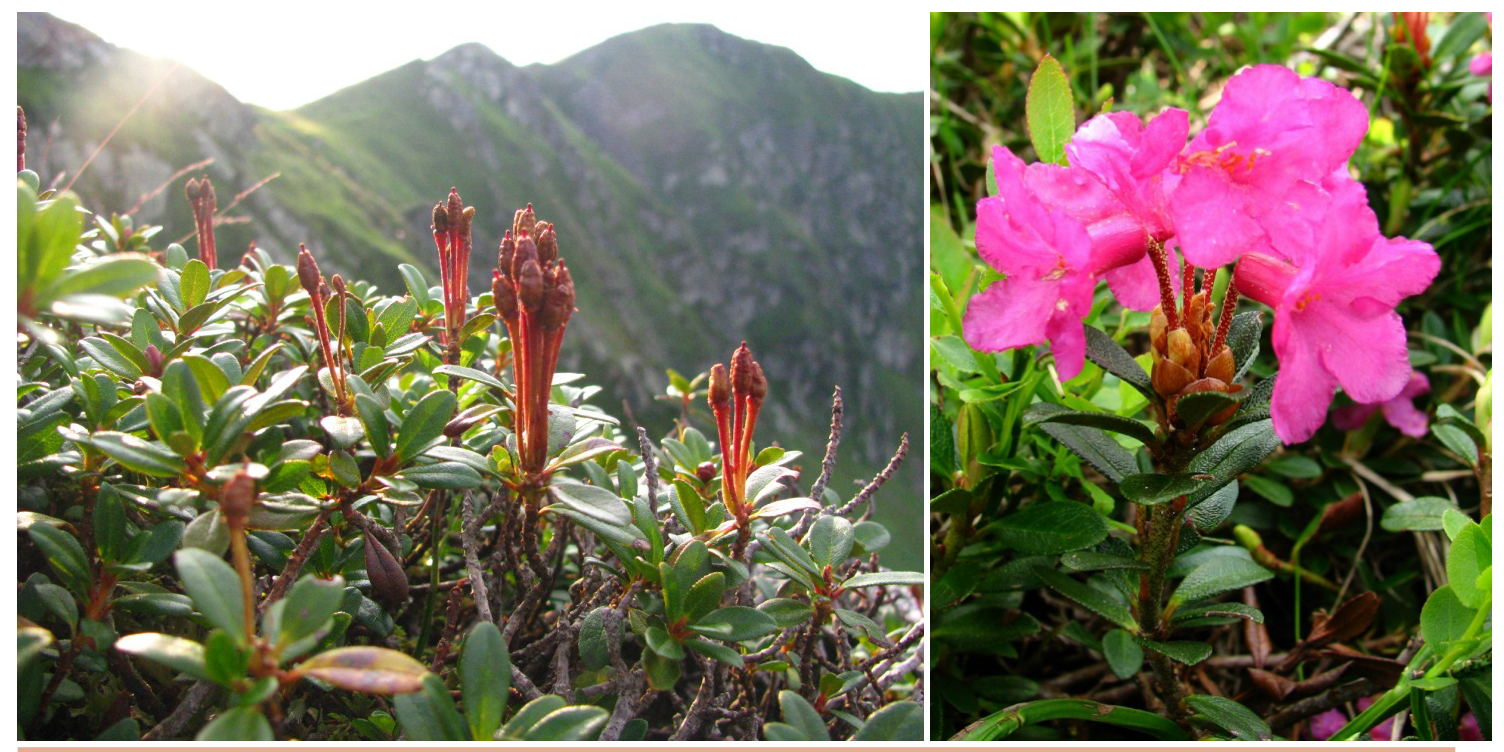

Figure 1 Rhododendron myrtifolium plant (Photo: Viktor Nachychko, Yevhen Sosnovsky)

First, the samples were examined by a microscopic Gram stain examination. Samples with Gram-negative results were inoculated on plates of nutrient agar, Clede agar, MacConkey's, and blood agar (Merck, Germany) and then incubated at $37^{\circ} \mathrm{C}$ for 24 hours. The colony that showed fermenting of lactose on MacConkey agar and Cled agar media were purified and identified according to their morphology as circular, rose-pink to red colonies on MacConkey agar medium and yellow colonies on Cled agar. The isolates were identified by some biochemical reactions (e.g. catalase enzyme, potassium hydroxide test, Indole and methyl red test, Voges Proskauer reaction, urease and citrate, H2S and oxidase test).

Susceptibility testing of the isolates was performed by disk diffusion according to the Guidelines of Clinical and Laboratory Standard Institute (CLSI, 2014). The following antimicrobial agents were used ( $\mu \mathrm{g}$ ): amikacin (30), ampicillin (10), aztreonam (30), ceftazidime (30), ciprofloxacin (5), cephalexin (30), gentamicin (10), erythromycin (15), imipenem (10), meropenem (10), clindamycin (2), aztreonam (30), norfloxacin (10), oxytetracycline (30), oxacillin (1), enrofloxacin (5), tetracycline (30), amoxicillin (25), piperacillin (100), piperacillintazobactam (100/10), tobramycin (10), ceftazidime (30), chloramphenicol (30), doxycycline (30), cefadroxil (30), pefloxacin (5), and cefepime (30). MIC was determined by E-test strips (according to manufacturer's instruction). The resistance breakpoints were the same as the ones defined by the National Committee for Clinical Laboratory Standards (NCCLS, 2000).

Phenotypic Disc Confirmatory Test was performed as recommended by the CLSI (Clinical and Laboratory Standards Institute, 2014). The antibacterial susceptibility profile of the isolates revealed that many isolated strains were classified as multi-drug resistant (MDR) bacteria.

For the current study, four bacterial strains were used for the study of susceptibility or resistance of bacteria to the phytochemicals: 
- Isolate 1 - Citrobacter freundii strain was susceptible to all antibiotics used;

- Isolate 2 - Enterobacter cloacae strain was resistant to the amoxicillin, cefuroxime, trimethoprim-sulphamethoxazole, and cefotaxime;

- Isolate 3 - Klebsiella pneumoniae was resistant to piperacillin-tazobactam $(100 / 10 \mu \mathrm{g})$, gentamicin $(10 \mu \mathrm{g})$, tobramycin $(10 \mu \mathrm{g})$, and ciprofloxacin $(5 \mu \mathrm{g})$;

- Isolate 4 - Escherichia coli, not $\beta$-lactamase (ESBL)-producing strain, was a sensitive strain to antibiotics tested.

\section{Bacterial Growth Inhibition Test by the Disk Diffusion Method}

Strains tested were plated on TSA medium (Tryptone Soy Agar) and incubated for $24 \mathrm{hr}$ at $25{ }^{\circ} \mathrm{C}$. Then the suspension of microorganisms was suspended in sterile PBS and the turbidity adjusted equivalent to that of a 0.5 McFarland standard. Muller-Hinton agar plates were inoculated with $200 \mu \mathrm{l}$ of standardized inoculum $\left(10^{8} \mathrm{CFU} / \mathrm{mL}\right)$ of the bacterium and spread with sterile swabs. Sterile filter paper discs impregnated by sample were applied over each of the culture plates, 15 min after bacteria suspension was placed. The antimicrobial susceptibility testing was done on Muller-Hinton agar by the disc diffusion method (KirbyBauer disk diffusion susceptibility test protocol) (Bauer et al., 1966). A negative control disc impregnated by sterile ethanol was used in each experiment. After culturing bacteria on Mueller-Hinton agar, the disks were placed on the same plates and incubated for $24 \mathrm{hr}$ at $37^{\circ} \mathrm{C}$. The assessment of antimicrobial activity was based on the measurement of the diameter of the inhibition zone formed around the disks.

The diameters of the inhibition zones were measured in millimeters and compared with those of the control and standard susceptibility disks. The activity was evidenced by the presence of a zone of inhibition surrounding the well. Each test was repeated six times.

\section{Statistical analysis}

Statistical analysis of the data obtained was performed by employing the mean \pm standard error of the mean (S.E.M.). All variables were tested for normal distribution using the Kolmogorov-Smirnov test $(p>0.05)$. In order to find significant differences (significance level, $p<0.05$ ) between groups, the Kruskal-Wallis test by ranks was applied to the data (Zar, 1999). All statistical analyses were performed using Statistica8.0 software (StatSoft, Poland). The following zone diameter criteria were used to assign susceptibility or resistance of bacteria to the phytochemicals tested: Susceptible $(S) \geq 15 \mathrm{~mm}$, Intermediate $(I)=11-14 \mathrm{~mm}$, and Resistant $(R) \leq 10 \mathrm{~mm}$ (Okoth et al., 2013).

\section{Results and discussion}

The ability of the ethanolic extract obtained from leaves of R. myrtifolium to inhibit Citrobacter freundii, Enterobacter cloacae, Klebsiella pneumoniae, and Escherichia coli growth was determined in this study. The results revealed that extract exerts antibacterial activity against Citrobacter freundii. However, the Enterobacter cloacae, Klebsiella pneumoniae, and Escherichia coli were resistant to $R$. myrtifolium leaf extract. Maximum in vitro inhibition was scored against Citrobacter freundii, followed by Escherichia coli, Klebsiella 
pneumoniae, and Enterobacter cloacae, which presented inhibition zones of $(12.1 \pm 0.9) \mathrm{mm}$, $(9.1 \pm 0.5) \mathrm{mm},(7.5 \pm 0.6) \mathrm{mm}$, and $(7.2 \pm 0.5) \mathrm{mm}$, respectively. In the case of the positive controls, $96 \%$ ethanol possesses a mild antibacterial effect, which presented inhibition zones of $(6.5 \pm 0.7) \mathrm{mm}$ (Figure 2).

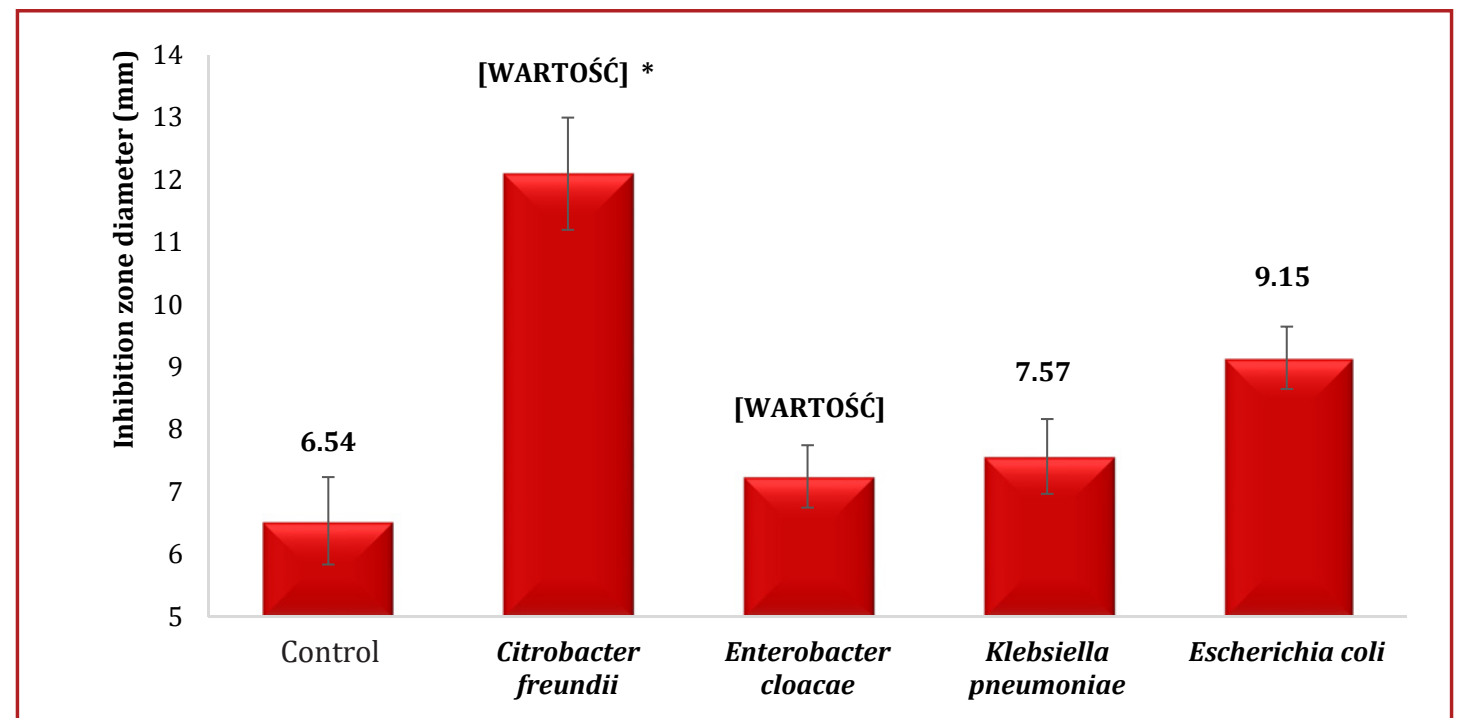

Figure 2 The mean of inhibition zone diameters of the ethanolic extract obtained from leaves of Rhododendron myrtifolium against Citrobacter freundii, Enterobacter cloacae, Klebsiella pneumoniae, and Escherichia coli strains locally isolated ( $\mathrm{M} \pm \mathrm{m}, n=6)$

$*$ - the changes are statistically significant $(p<0.05)$ compared to the control group $(96 \%$ ethanol)

Detailed data regarding the zones of inhibition by the ethanolic extract obtained from leaves of R. myrtifolium against Citrobacter freundii and Enterobacter cloacae were recorded and presented in Figure 2.

In line with the growing interest in the antibacterial potential of different plants, we examined the antibacterial properties of the ethanolic extract obtained from $R$. myrtifolium against Rhododendron myrtifolium leaves against Citrobacter freundii, Enterobacter cloacae, Klebsiella pneumoniae, and Escherichia coli strains. The results from the screening study performed by the disc diffusion method revealed that $R$. myrtifolium possesses a mild antibacterial activity against $C$. freundii (Figure 2, 3A).

The results of this study are consistent with other studies that have previously been reported that extracts of Rhododendron leaves have antibacterial activity against resistant bacteria strains. Crude extracts of Rhododendron leaves were tested for their antibacterial activity using agar diffusion and minimum inhibitory concentration assays and results were presented in the study of Hakeem Said et al. (2017). The antibacterial activity of $R$. collettianum Aitch. \& Hemsl. was compared to a series of inactive extracts. Three metabolites were found to distinguish $R$. collettianum from other species indicating the ability to suggest potential bioactive substances (Hakeem Said et al., 2017). 


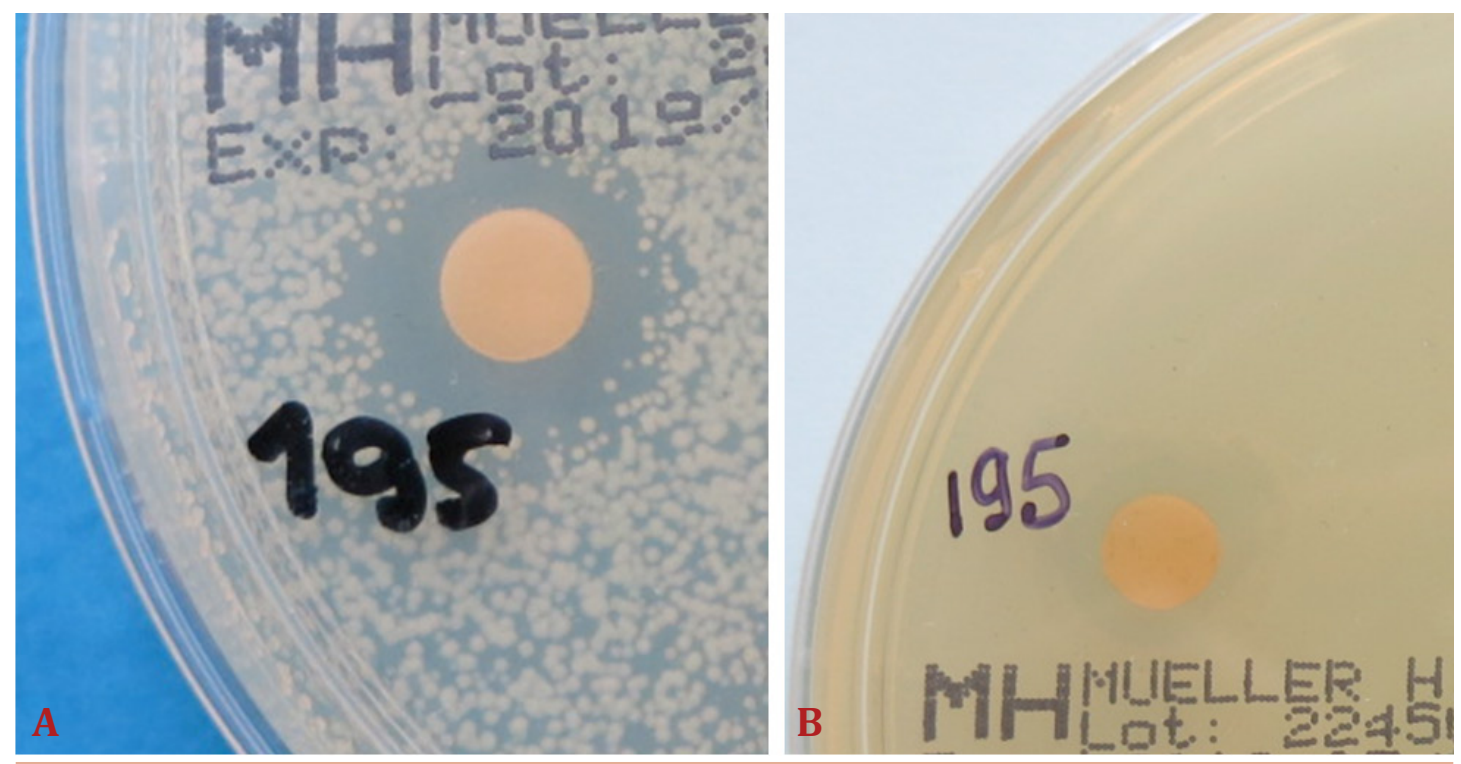

Figure 3 Antimicrobial activity of ethanolic extract obtained from leaves of $R$. myrtifolium against Citrobacter freundii (A) and Enterobacter cloacae (B) measured as inhibition zone diameter

The polyphenolic profile of fruits, flowers, and leaves of different ages of Rhododendron ambiguum Hemsl. and Rhododendron cinnabarinum Hook. f. was studied by Shrestha et al. (2017). Fifty-nine different polyphenols including isomers were identified in these species. The leaves and fruits contained more polyphenols than the flowers. Also, the antibacterial activity of these parts (leaves, fruits, and flowers) against gram-positive bacteria was studied. There was no bioactivity observed for crude extracts of all samples against Escherichia coli. Against Gram-positive bacteria, the bioactivity of $R$. ambiguum ranged between 0.5 and $0.7 \mathrm{~cm}$, while for $R$ cinnabarinum between 0.5 and $0.8 \mathrm{~cm}$. Antibacterial effects of fruit and leaf extracts were in the same order of magnitude. However, there was a reduced antibacterial activity observed for the flowers of $R$. cinnabarinum and $R$. ambiguum. This could be due to the evolutionary aspect as flowers have a short blooming period in a year compared to the leaves and fruits. In general, $B$. thioparus was the most sensitive bacteria species towards the plant parts for both Rhododendron species (Shrestha et al., 2017).

A higher antibacterial effect of Rhododendron species against Gram-positive and higher effect for $R$. cinnabarinum was demonstrated in the antibacterial screening by Rezk et al. (2015a). Erwinia amylovora 1189 (wild type), Escherichia coli TG1 (wild type), Pseudomonas syringae DC3000 (wild type) as well as the respective mutants with deletions in acrAB, tolC, or mexAB. Additionally, knockout mutants of E. amylovora and E. coli with deletions in both, acrAB and tolC were subjected to the antimicrobial analysis. The leaf extracts of 17 Rhododendron species exhibited significant growth-inhibiting activities against Gram-positive bacteria. In contrast, only very few of the leaf extracts affected the growth of Gram-negative bacteria. Five out of the 120 Rhododendron leaf extracts showed no growth inhibitory activity against any of the Gram-positive tester organisms: R. elliottii Watt ex Brandis, R. hylaeum Balfour \& Farrer, R. ponticum L., R. keiskei Miquel, and R. eriocarpum (Hayata) Nakai. However, crude extracts 
obtained from 38 other Rhododendron species exhibited moderate antimicrobial activity against 12 out of the 26 tested bacterial species. The crude extracts derived from the remaining 77 Rhododendron species showed significant bioactivities against at least one of the 26 tester organisms. The spectrum of microbial susceptibilities towards Rhododendron extracts varied widely and showed dramatic differences, i.e. some of the tester organisms were susceptible to leaf extracts from most of the Rhododendron species while other bacterial tester organisms were susceptible towards very few Rhododendron leaf extracts. Bacillus thioparus was the most sensitive tester species susceptible to all 77 potentially bioactive Rhododendron leaf extracts. The other tested Gram-positive bacteria showed similar susceptibility only towards leaf extracts derived from the 17 most bioactive Rhododendron species. All leaf extracts with antimicrobial bioactivity were extracted from representatives of the subgenus Rhododendron, with 15 from the sub-section Rhododendron and two belonging to the section Pogonanthum. The use of bacterial multidrug efflux pump mutants revealed remarkable differences in the susceptibility towards Rhododendron leaf extract treatment. In contrast, susceptibilities of the tested Gram-negative bacterial strains were classified into either low or moderate extent. Only one Gram-negative species, Sinorhizobium meliloti, belonging to the order of $\alpha$-proteobacteria exhibited susceptibility to most of the bioactive Rhododendron extracts and was therefore similar in its susceptibility to the majority of Gram-positive bacteria. The results of Rezk et al. (2015a) suggested that common genetic traits are responsible for the production of bioactive secondary metabolite(s) which act primarily on Gram-positive organisms, and which may affect Gramnegative bacteria independence of the activity of multidrug efflux pumps in their cell envelope. In other studies, Rezk et al. (2015b) have assessed the cytotoxicity exerted by leaf extracts from plants of the genus Rhododendron towards epidermal keratinocytes and intestine epithelial cells. Different concentrations of DMSO-dissolved remnants of crude methanol Rhododendron leaf extracts were incubated for $24 \mathrm{~h}$ with cultured epidermal keratinocytes (human HaCaT cell line) and epithelial cells of the intestinal mucosa (rat IEC6 cell line) and tested for their cytotoxic potential. In particular, the cytotoxic potencies of the compounds contained in antimicrobial Rhododendron leaf extracts were assessed by quantifying their effects on plasma membrane integrity, cell viability and proliferation rates, cellular metabolism, cytoskeletal architecture, and determining initiation of cell death pathways by morphological and biochemical means. Extracts of almost all Rhododendron species, when applied at $500 \mu \mathrm{g} / \mathrm{mL}$, were potent in negatively affecting both keratinocytes and intestine epithelial cells, except material from $R$. hippophaeoides var. hippophaeoides. Extracts of $R$. minus and $R$. racemosum were non-toxic towards both mammalian cell types when used at $50 \mu \mathrm{g} / \mathrm{mL}$, which was equivalent to their minimal inhibitory concentration against bacteria. At this concentration, leaf extracts from three other highly potent antimicrobial Rhododendron species proved non-cytotoxic against one or the other mammalian cell type: Extracts of $R$. ferrugineum were non-toxic towards IEC6 cells, and extracts of $R$. rubiginosum, as well as $R$. concinnum, did not affect HaCaT cells. In general, keratinocytes proved more resistant than intestine epithelial cells against the treatment with compounds contained in Rhododendron leaf extracts (Rezk et al., 2015b).

The essential oil of Rhododendron anthopogon was investigated by Innocenti et al. (2010). The anti-microbial activity of $R$. anthopogon essential oil was evaluated by reference microdilution assays against a series of Gram-positive and Gram-negative reference strains. Gram-positive 
and Gram-negative bacteria: Staphylococcus aureus (ATCC 20202), Enterococcus fecalis (ATCC 29216), Bacillus subtilis (ATCC 6633), Escherichia coli (ATCC 25922), Pseudomonas aeruginosa (ATCC 27753) were evaluated to measure the anti-bacterial activity; a total of six strains of Candida albicans and nine strains of Candida spp., all clinical isolates, were selected to test the antifungal activity. Furthermore, Mycobacterium tuberculosis reference strain H37Rv was employed to determine the anti-tubercular activity. Although topical anti-inflammatory activity was obtained only at very high concentrations, a remarkable anti-microbial activity was detected against B. subtilis and M. tuberculosis. Moreover, the R. anthopogon essential oil inhibited most clinical strains of Candida spp. at doses comparable with reference antifungal drugs and the strongest activity was found against a clinical isolate of $C$. pseudotropicalis. Moreover, the oil was able to reduce cancer cell growth independently of the cell line and the treatment protocols used (Innocenti et al., 2010).

The properties of Rhododendron species which inhibit bacterial growth are mainly related to their chemical components including phenolic compounds, especially flavonoids, essential oils, procyanidins, chromones, terpenoids, and steroids against various Gram-positive and Gramnegative bacteria. It has many biological properties such as antioxidant, anti-inflammatory, antiviral, antibacterial, anticancer, antidiabetic, immunomodulatory, cardioprotective and hepatoprotective among others due to their polyphenolic constituents (Demir et al., 2016).

The biological activities of major procyanidins isolated from the leaf extract of $R$. formosanum Hemsl. were investigated by Wang et al. (2015). Four compounds, including two procyanidin dimers, procyanidin A1 (1) and B3 (2), and two procyanidin trimmers, procyanidin C4 (4) and cinnamtannin D1 (5), were isolated and identified on the basis of spectroscopic data. The structure of a new procyanidin dimer, rhodonidin A (3), was elucidated by 2D-NMR, CD spectrum, and MS. The procyanidin trimmers and rhodonidin A are reported for the first time in Ericaceae. The biological activities of these procyanidins were evaluated using anti-bacterial and anti-oxidative assays. Only the new compound 3 demonstrated strong antibacterial activity against Staphylococcus aureus at a MIC value of $4 \mu \mathrm{g} / \mathrm{mL}$. All compounds showed pronounced antioxidant activities and the activities are enhanced as the amount of OH groups in procyanidins increased (Wang et al., 2015).

The proanthocyanidins of the leaves of 16 taxa of the Rhododendron genus [Rhododendron catawbiense Michx. cv. Grandiflorum, Rhododendron ,Cunningham's White' (syn. Rhododendron caucasicum Pall. $\times$ Rhododendron ponticum L.), Rhododendron smirnowii Trautv., Rhododendron calophytum Franch., Rhododendron dichroanthum ssp. scyphocalyx (Balf. f. \& Forrest) Cowan, Rhododendron micranthum Turcz., Rhododendron praevernum Hutch., Rhododendron ungernii Trautv., Rhododendron kaempferi Planch., Rhododendron degronianum ssp. heptamerum var. hondoense (Nakai) H. Hara, Rhododendron fortunei Lindl., Rhododendron ponticum L., Rhododendron galactinum Balf. f. ex Tagg., Rhododendron oreotrephes W. W. Sm., Rhododendron brachycarpum ssp. brachycarpum D. Don ex G. Don, and Rhododendron insigne Hemsl. \& E. H. Wilson] were investigated qualitatively by liquid chromatography-mass spectrometry by Jaiswal et al. (2012). Four caffeoylquinic acids, six p-coumaroylquinic acids, epigallocatechin, gallocatechin, catechin, epicatechin, epigallocatechin gallate, catechin gallate, epicatechin gallate, gallocatechin gallate, two quercetin-0-hexosides, quercetin-0-galloyl-hexoside, quercetin-0-pentoside, 
quercetin-0-rhamnoside, quercetin-0-pentoside-0-hexoside, quercetin-0-rhamnoside-0hexoside, quercetin-O-feruloyl-hexoside, quercetin-O-(p-hydroxy)benzoyl-hexoside, taxifolin-Opentoside, myricetin-0-rhamnoside, two myricetin-0-pentosides, three myricetin-0-hexosides, and two myricetin-0-galloyl-hexosides were detected (Jaiswal et al., 2012).

The seven flavanones were isolated from the aerial parts of Rhododendron hainanense Merr. and were tested for their antimicrobial activities against six bacteria and six plant pathogenic fungi by Li et al. (2016). Within the series of flavanones tested, farrerol (1) displayed moderate antibacterial activities against Bacillus cereus, B. subtilis, Pseudomonas aeruginosa, Staphylococcus aureus, Escherichia coli, and Erwinia carotovora, with MICs ranging from 15.6 to $125 \mu \mathrm{g} / \mathrm{mL}$. Furthermore, farrerol (1) exhibited excellent inhibitory activities against six plant pathogenic fungi: Fusarium oxysporum sp. niveum, Colletotrichum gloeosporioides, Penicillium italicum, Rhizoctonia solani, Fusarium oxysporum sp. cubenserace and Phytophthora melonis, with EC50 values of 9, 18, 35, 39, 46 and $66 \mu \mathrm{g} / \mathrm{mL}$, respectively (Li et al., 2016).

The antioxidant properties and cytotoxic activity of species belonging to the Rhododendron genus were also studied. For example, Demir et al. (2016) have evaluated the antioxidant properties and cytotoxic activity of the extract of flowers of Rhododendron luteum Sweet on three cancers (human breast, colon, and liver carcinoma) and human foreskin fibroblast cells for the first time. R. luteum extract exhibited selective cytotoxicity against colon and liver cancer cells compared to normal fibroblast cells, while this selective cytotoxicity was not observed in breast cancer cells (Demir et al., 2016). The essential oil of Rhododendron anthopogon D. Don. showed marginal antibacterial and cytotoxic activities against MCF-7, MDA-MB-231, and 5637, but no antifungal effects (Dosoky et al., 2016).

Fifty Rhododendron honey samples obtained from the Black Sea Region of Turkey were also screened for total phenolic content and for potential antioxidant activity by Silici et al. (2010). The antimicrobial activity was studied by using eleven bacteria and two yeasts. The 13 microorganisms containing eleven bacteria and two yeasts were used as test organisms: Aeromonas hydrophila ATCC 7965, Bacillus cereus FMC 19, Bacillus subtilis ATCC 6630, Escherichia coli 0157:H7 RS_932, Listeria monocytogenes 1/2B, Mycobacterium smegmatis RUT, P. mirabilis BC_3624, P. aeruginosa ATCC 27853, Salmonella typhimurium NRRLE_4463, Staphylococcus aureus ATCC 28213, Candida albicans ATCC 1223, Saccharomyces cerevisiae BC 5461, and Yersinia enterocolitica ATCC 1501. The honey samples showed the highest antimicrobial activity against $P$. aeruginosa and $P$. mirabilis. In addition, S. aureus, A. hydrophila, L. monocytogenes, $B$. subtilis, $M$. smegmatis, and $S$. typhimurium were moderately sensitive to the antimicrobial activity of Rhododendron honey. However B. cereus, E. coli 0157:H7, and $Y$. enterocolitica were the most resistant microorganisms. In addition, honey samples also had no inhibitory effects on two yeasts; C. albicans and S. cerevisiae (Silici et al., 2010).

\section{Conclusions}

The results revealed that extract exerts antibacterial activity against Citrobacter freundii. However, the Enterobacter cloacae, Klebsiella pneumoniae, and Escherichia coli were resistant to $R$. myrtifolium leaf extract. Maximum in vitro inhibition was scored against Citrobacter freundii, followed by Escherichia coli, Klebsiella pneumoniae, and Enterobacter cloacae. It can be 
concluded that Rhododendron myrtifolium leaves extract can be as complementary medicine in treating diseases caused by multidrug-resistant strains of Citrobacter freundii. However, further investigation is needed to determine the bioavailability of the active compounds and to determine the dose and toxicity before it can be used as therapeutic agents.

\section{References}

BAUER, A.W., KIRBY, W.M., SHERRIS, J.C., TURCK, M. 1966. Antibiotic susceptibility testing by a standardized single disk method. In Am. J. Clin. Pathol., vol. 45(4), p. 493-496.

BORATYŃSKI, A., PIWCZYŃSKI, M., DIDUKH, Y.P., TASENKEVICH, L., ROMO, A., RATYŃSKA, H. 2006. Distribution and phytocoenotic characteristics of relict populations of Rhododendron myrtifolium (Ericaceae) in the Ukrainian Carpathians. In Pol. Bot. Stud., vol. 22, p. 53-62.

CLSI. Performance Standards for Antimicrobial Susceptibility Testing. Clinical and Laboratory Standards Institute; Wayne, PA, USA: 2014. CLSI M100-S24.

CULLEN, J., 1980. A revision of Rhododendron. I. Subgenus Rhododendron sections Rhododendron and Pogonanthum. In Notes Roy. Bot. Gard. Edinb., vol. 39(1), p. 1-207.

CULLEN, J. 2005. Hardy Rhododendron Species: A guide to Identification. Timber Press, Portland (Published in association with the Royal Botanic Garden Edinburgh).

DEMIR, S., TURAN, I., ALIYAZICIOGLU, Y. 2016. Selective cytotoxic effect of Rhododendron luteum extract on human colon and liver cancer cells. In J. BUON, vol. 21(4), p. 883-888.

DIHORU, G., BORUZ, V. 2014. The list of main spontaneous medicinal plants from Romania. In Ann. Univ. Craiova Agric. Montanol. Cadastre Ser., vol. 44(1), p. 328-344.

DOSOKY, N.S., SATYAL, P., POKHAREL, S., SETZER, W.N. 2016. Chemical composition, enantiomeric distribution, and biological activities of Rhododendron anthopogon leaf essential oil from Nepal. In Nat. Prod. Commun., vol. 11(12), p. 1895-1898.

GESCHER, K., KÜHN, J., HAFEZI, W., LOUIS, A., DERKSEN, A., DETERS, A., LORENTZEN, E., HENSEL, A. 2011. Inhibition of viral adsorption and penetration by an aqueous extract from Rhododendron ferrugineum L. as antiviral principle against herpes simplex virus type-1. In Fitoterapia, vol. 82(3), p. 408-413. https://doi.org/10.1016/j.fitote.2010.11.022

HAKEEM SAID, I., REZK, A., HUSSAIN, I., GRIMBS, A., SHRESTHA, A., SCHEPKER, H., BRIX, K., ULLRICH, M.S., KUHNERT, N. 2017. Metabolome comparison of bioactive and inactive Rhododendron extracts and identification of an antibacterial Cannabinoid(s) from Rhododendron collettianum. In Phytochem. Anal., vol. 28(5), p. 454-464. https://doi.org/10.1002/pca.2694

INNOCENTI, G., DALL'ACQUA, S., SCIALINO, G., BANFI, E., SOSA, S., GURUNG, K., BARBERA, M., CARRARA, M. 2010. Chemical composition and biological properties of Rhododendron anthopogon essential oil. In Molecules, vol. 15(4), p. 2326-2338. https://doi.org/10.3390/molecules15042326

IRVING, E., HEBDA, R. 1993. Concerning the origin and distribution of rhododendrons. In J. Am. Rhododendron Soc., vol. 47(3), p. 139-146, p. 157-162.

JAISWAL, R., JAYASINGHE, L., KUHNERT, N. 2012. Identification and characterization of proanthocyanidins of 16 members of the Rhododendron genus (Ericaceae) by tandem LC-MS. In J. Mass Spectrom., vol. 47(4), p. 502-515. https://doi.org/10.1002/jms.2954

LI, Y., ZHAO, J., GAO, K. 2016. Activity of Flavanones Isolated from Rhododendron hainanense against Plant Pathogenic Fungi. In Nat. Prod. Commun., vol. 11(5), p. 611-612.

LOUIS, A., PETEREIT, F., LECHTENBERG, M., DETERS, A., HENSEL, A. 2010. Phytochemical characterization of Rhododendron ferrugineum and in vitro assessment of an aqueous extract on cell toxicity. In Planta Med., vol. 76(14), p. 1550-1557. https://doi.org/10.1055/s-0029-1241016

MAH, M.W., MEMISH, Z.A. 2000. Antibiotic resistance. An impending crisis. In Saudi Med. J., vol. 21(12), p. 1125-1129. 
MIRCEA, T., 2005. Contribution to the study of the anatomical structure of ericaceous leaves species. In Not. Bot. Hort. Agrobot. Cluj-Napoca, vol. 33, p. 15-19.

NEDELCHEVA, A., DRAGANOV, S. 2014. Bulgarian medical ethnobotany: the power of plants in pragmatic and poetic frames. In Pieroni, A., Quave, C.L. (eds.) Ethnobotany and Biocultural Diversities in the Balkans. Springer, New York, pp. 45-65. https://doi.org/10.1007/978-1-4939-1492-0 4

OKOTH, D.A., CHENIA, H.Y., KOORBANALLY, N.A. 2013. Antibacterial and antioxidant activities of flavonoids from Lannea alata (Engl.) Engl. (Anacardiaceae). In Phytochem. Lett., vol. 6, p. 476-481. https://doi.org/10.1016/j.phytol.2013.06.003

POPESCU, R., KOPP, B. 2013. The genus Rhododendron: an ethnopharmacological and toxicological review. In J. Ethnopharmacol., vol. 147(1), p. 42-62. https://doi.org/10.1016/j.jep.2013.02.022

RADJI, M., AGUSTAMA, R.A., ELYA, B., TJAMPAKASARI, C.R. 2013. Antimicrobial activity of green tea extract against isolates of methicillin-resistant Staphylococcus aureus and multi-drug resistant Pseudomonas aeruginosa. In Asian Pac. J. Trop. Biomed., vol. 3(8), p. 663-667. https://doi. org/10.1016/S2221-1691(13)60133-1

REZK, A., AL-HASHIMI, A., JOHN, W., SCHEPKER, H., ULLRICH, M.S., BRIX, K. 2015b. Assessment of cytotoxicity exerted by leaf extracts from plants of the genus Rhododendron towards epidermal keratinocytes and intestine epithelial cells. In BMC Complement. Altern. Med., vol. 15, p. 364. https://doi.org/10.1186/s12906-015-0860-8

REZK, A., NOLZEN, J., SCHEPKER, H., ALBACH, D.C., BRIX, K., ULLRICH, M.S. 2015a. Phylogenetic spectrum and analysis of antibacterial activities of leaf extracts from plants of the genus Rhododendron. In BMC Complement. Altern. Med., vol. 15, p. 67. https://doi.org/10.1186/s12906-015-0596-5

RICE, L.B. 2008. Federal funding for the study of antimicrobial resistance in nosocomial pathogens: no ESKAPE. In J. Infect. Dis., vol. 197(8), p. 1079-1081. https://doi.org/10.1086/533452

RÍOS, J.L., RECIO, M.C. 2005. Medicinal plants and antimicrobial activity. In J. Ethnopharmacol., vol. 100(1-2), p. 80-84. https://doi.org/10.1016/i.jep.2005.04.025

RIVERS, M.C. 2017. Rhododendron myrtifolium. In The IUCN Red List of Threatened Species 2017: e.T83772628A86136306. Available from https://www.iucnredlist.org/ species/83772628/86136306 [accessed 26 October 2019].

SEEPHONKAI, P., POPESCU, R., ZEHL, M., KRUPITZA, G., URBAN, E., KOPP, B. 2011. Ferruginenes A-C from Rhododendron ferrugineum and their cytotoxic evaluation. In J. Nat. Prod., vol. 74(4), p. 712717. https://doi.org/10.1021/np100778k

SHRESTHA, A., REZK, A., SAID, I.H., VON GLASENAPP, V., SMITH, R., ULLRICH, M.S., SCHEPKER, H., KUHNERT, N. 2017. Comparison of the polyphenolic profile and antibacterial activity of the leaves, fruits and flowers of Rhododendron ambiguum and Rhododendron cinnabarinum. In BMC Res. Notes, vol. 10(1), p. 297. https://doi.org/10.1186/s13104-017-2601-1

SILICI, S., SAGDIC, O., EKICI, L. 2010. Total phenolic content, antiradical, antioxidant and antimicrobial activities of Rhododendron honeys. In Food Chemistry, vol. 121(1), p. 238-243. https://doi. org/10.1016/j.foodchem.2009.11.078

SOSNOVSKY, Y., NACHYCHKO, V., PROKOPIV, A., HONCHARENKO, V. 2017. Leaf architecture in Rhododendron subsection Rhododendron (Ericaceae) from the Alps and Carpathian Mountains: taxonomic and evolutionary implications. In Flora, vol. 230, p. 26-38. https://doi.org/10.1016/j.flora.2017.03.003

VOLOSCHUK, M., PROKOPIV, A. 2011. The peculiarities of life-form formation in Rhododendron myrtifolium Schott et Kotschy in the Ukrainian Carpathians. In Stud. Biol., vol. 5(1), p. 149-158. https://doi.org/10.30970/sbi.0501.140

WANG, C.M., HSU, Y.M., JHAN, Y.L., TSAI, S.J., LIN, S.X., SU, C.H., CHOU, C.H. 2015. Structure Elucidation of Procyanidins Isolated from Rhododendron formosanum and Their Anti-Oxidative and AntiBacterial Activities. In Molecules, vol. 20(7), p. 12787-12803. https://doi.org/10.3390/ molecules200712787

ZAR, J.H. 1999. Biostatistical Analysis. $4^{\text {th }}$ ed., Prentice-Hall Inc., Englewood Cliffs, New Jersey. 